University of Nebraska - Lincoln

DigitalCommons@University of Nebraska - Lincoln

Other Publications in Zoonotics and Wildlife

Disease

Wildlife Disease and Zoonotics

2003

\title{
A prion protein epitope selective for the pathologically misfolded conformation
}

\author{
Eustache Paramithiotis \\ Caprion Pharmiceuticals Inc. \\ Marc Pinard \\ Caprion Pharmiceuticals Inc. \\ Trebor Lawton \\ IDEXX Laboratories Inc. \\ Sylvie LaBoissiere \\ Caprion Pharmiceuticals Inc.
}

Valerie I. Leathers

IDEXX Laboratories Inc.

See next page for additional authors

Follow this and additional works at: https://digitalcommons.unl.edu/zoonoticspub

Part of the Veterinary Infectious Diseases Commons

Paramithiotis, Eustache; Pinard, Marc; Lawton, Trebor; LaBoissiere, Sylvie; Leathers, Valerie I.; Zou, WenQuan; Estey, Lisa A.; Lamontagne, Julie; Lehto, Marty T.; Kondejewski, Leslie H.; Francoeur, Gregory P.; Papadopoulos, Maria; Haghighat, Ashkan; Spatz, Stephen J.; Head, Mark; Will, Robert; Ironside, James; O'Rourke, Katherine I.; Tonelli, Quentin; Ledebur, Harry C.; Chakrabartty, Avi; and Cashman, Neil R., "A prion protein epitope selective for the pathologically misfolded conformation" (2003). Other Publications in Zoonotics and Wildlife Disease. 148.

https://digitalcommons.unl.edu/zoonoticspub/148

This Article is brought to you for free and open access by the Wildlife Disease and Zoonotics at DigitalCommons@University of Nebraska - Lincoln. It has been accepted for inclusion in Other Publications in Zoonotics and Wildlife Disease by an authorized administrator of DigitalCommons@University of Nebraska - Lincoln. 


\section{Authors}

Eustache Paramithiotis, Marc Pinard, Trebor Lawton, Sylvie LaBoissiere, Valerie I. Leathers, Wen-Quan Zou, Lisa A. Estey, Julie Lamontagne, Marty T. Lehto, Leslie H. Kondejewski, Gregory P. Francoeur, Maria Papadopoulos, Ashkan Haghighat, Stephen J. Spatz, Mark Head, Robert Will, James Ironside, Katherine I. O'Rourke, Quentin Tonelli, Harry C. Ledebur, Avi Chakrabartty, and Neil R. Cashman 


\section{A prion protein epitope selective for the pathologically misfolded conformation}

Eustache Paramithiotis ${ }^{1}$, Marc Pinard ${ }^{1}$, Trebor Lawton ${ }^{2}$, Sylvie LaBoissiere ${ }^{1}$, Valerie L Leathers ${ }^{2}$, Wen-Quan Zou $^{6}$, Lisa A Estey ${ }^{2}$, Julie Lamontagne ${ }^{1}$, Marty T Lehto ${ }^{6}$, Leslie H Kondejewski ${ }^{1}$, Gregory P Francoeur ${ }^{2,8}$, Maria Papadopoulos ${ }^{1}$, Ashkan Haghighat ${ }^{1}$, Stephen J Spatz ${ }^{2,9}$, Mark Head ${ }^{3}$, Robert Will ${ }^{3}$, James Ironside ${ }^{3}$, Katherine O'Rourke ${ }^{4}$, Quentin Tonelli ${ }^{2}$, Harry C Ledebur ${ }^{1}$, Avi Chakrabartty ${ }^{5}$ \& Neil R Cashman ${ }^{1,5,6,7}$

Conformational conversion of proteins in disease is likely to be accompanied by molecular surface exposure of previously sequestered amino-acid side chains. We found that induction of $\beta$-sheet structures in recombinant prion proteins is associated with increased solvent accessibility of tyrosine. Antibodies directed against the prion protein repeat motif, tyrosine-tyrosinearginine, recognize the pathological isoform of the prion protein but not the normal cellular isoform, as assessed by immunoprecipitation, plate capture immunoassay and flow cytometry. Antibody binding to the pathological epitope is saturable and specific, and can be created in vitro by partial denaturation of normal brain prion protein. Conformation-selective exposure of Tyr-Tyr-Arg provides a probe for the distribution and structure of pathologically misfolded prion protein, and may lead to new diagnostics and therapeutics for prion diseases.

The prion diseases are a group of neurodegenerative disorders characterized by neuronal cell loss, spongiform change, gliosis and deposition of abnormal amyloid protein ${ }^{1-3}$. Animal prion diseases include scrapie in sheep and goats, bovine spongiform encephalopathy (BSE) in cattle, chronic wasting disease in deer and elk, transmissible mink encephalopathy, and feline spongiform encephalopathy in domestic and exotic cats. In humans, recognized prion diseases include kuru, classical Creutzfeldt-Jakob disease (CJD), GerstmannSträussler-Scheinker syndrome (GSS), fatal familial insomnia and variant Creutzfeldt-Jakob disease (variant CJD). Of particular recent concern is variant CJD, presumably resulting from oral inoculation of BSE prions. Currently, cases of this emergent prion disease have been identified in the United Kingdom, France, the Republic of Ireland, Hong Kong, Italy, the United States and Canada ${ }^{2,3}$. There is no authoritative consensus on the ultimate extent of the primary variant CJD epidemic, nor to the risk of secondary human-tohuman transmission by iatrogenic routes.

The 'protein-only' hypothesis contends that prion infectivity resides in pathologically misfolded prion protein (designated $\operatorname{PrP}^{\mathrm{Sc}}$, $\operatorname{Pr}^{\mathrm{BSE}}$, or $\mathrm{Pr} \mathrm{P}^{\mathrm{CJD}}$, depending on the species of origin; $\mathrm{PrP}^{\mathrm{Sc}}$ is used here to denote disease-associated PrP), which can 'recruit' cellular prion protein $\left(\mathrm{PrP}^{\mathrm{C}}\right)$ by a template-directed process ${ }^{1}$. PrP $\mathrm{P}^{\mathrm{Sc}}$ generally possesses partial protease resistance and high $\beta$-sheet content, unlike the protease-sensitive, $\alpha$-helix-rich $\operatorname{PrP}^{\mathrm{C}}$ (refs. 4-6). As a distinct structural isoform of $\mathrm{PrP}$, one would anticipate that $\mathrm{PrP}^{\mathrm{Sc}}$ should possess unique conformational epitopes. A 'shotgun' immunization of PrP-null mice with recombinant bovine PrP has yielded a single putative IgM monoclonal antibody to $\mathrm{PrP}^{\mathrm{Sc}}$ (ref. 7), the specificity of which has not been confirmed outside of the reporting laboratory (refs. 8,9 and data not shown). We now report that antibody access to the PrP repeat motif Tyr-Tyr-Arg defines a $\mathrm{PrP}^{\mathrm{Sc}}$-selective epitope.

\section{RESULTS}

PrP tyrosine exposure is dependent on conformation

$\mathrm{PrP}^{\mathrm{Sc}}$ is poorly soluble and tends to aggregate under physiological conditions ${ }^{4-6}$, properties often associated with molecular surface exposure of hydrophobic amino-acid side chains. We hypothesized that side chains not normally exposed to solvent might participate in the formation of unique immunological epitopes for selective antibody recognition of $\mathrm{PrP}^{\mathrm{Sc}}$. Low-pH treatment of recombinant $\mathrm{PrP}$ induces increased $\beta$-sheet content and promotes aggregation, perhaps modeling aspects of the conformational conversion of $\mathrm{PrP}^{\mathrm{C}}$ to $\mathrm{PrP}^{\mathrm{Sc}}$ in disease (refs. 10-12 and data not shown). We now report that low-pH treatment of full-length recombinant mouse PrP is accompanied by increased solvent exposure of tyrosine side chains, as indicated by increased tyrosine-specific fluorescence (Fig. 1a) and enhanced access to the collisional quenching agent acrylamide ${ }^{13}$ (Fig. 1b). In contrast, tryptophan-specific fluorescence was unchanged at low $\mathrm{pH}$ (Fig. 1a), with no observable change in acrylamide fluorescence quenching (data not shown). As virtually all tyrosine residues reside in the $\mathrm{C}$-ter-

${ }^{1}$ Caprion Pharmaceuticals Inc., 7150 Alexander-Fleming, St-Laurent, Quebec H4S 2C8, Canada. ${ }^{2}$ IDEXX Laboratories Inc., 1 IDEXX Drive, Westbrook, Maine 04092, USA. ${ }^{3}$ The National Creutzfeldt-Jakob Disease Surveillance Unit, Western General Hospital, Crewe Road, Edinburgh EH4 2XU, UK. ${ }^{4}$ USDA-ARS-ADRU, 3003 ADBF, Washington State University, Pullman, Washington 99164-6630, USA. ${ }^{5}$ Department of Medical Biophysics, University of Toronto, Ontario Cancer Institute, 610 University Avenue, Toronto, Ontario M5G 2M9, Canada. ${ }^{6}$ Centre for Research in Neurodegenerative Diseases, 6 Queen's Park Crescent West, University of Toronto, Toronto, Ontario M5S 3H2, Canada. ${ }^{7}$ Sunnybrook \& Women's College Health Sciences Centre, University of Toronto, 2075 Bayview Avenue, Toronto, Ontario M4N 3M5, Canada. ${ }^{8}$ Deceased. ${ }^{9}$ Present address: Vertex Inc., 130 Waverly Street, Cambridge, Massachusetts 02139-4242, USA. Correspondence should be addressed to N.R.C. (neil.cashman@utoronto.ca). 


\section{ARTICLES}

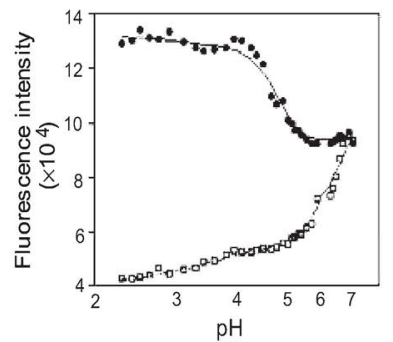

b

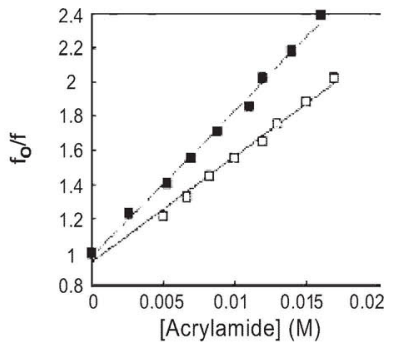

C

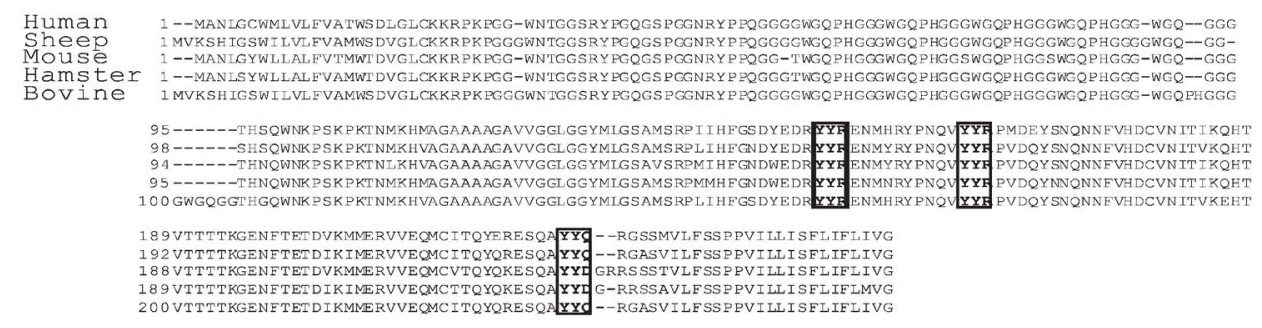

minal two-thirds of PrP, changes in tyrosine solvent access are probably indicative of conformational changes in this 'structured domain ${ }^{14-16}$, which also contributes to the infectious, protease-resistant fragment of $\mathrm{PrP}^{\mathrm{Sc}}$ (refs. 4-6).

\section{Tyr-Tyr-Arg antibodies selectively recognize $\mathrm{PrPSc}$}

The majority of tyrosine residues in the structured domain of $\operatorname{PrP}$ appear in pairs conserved across mouse, hamster, sheep, bovine and human PrP (Fig. 1c). Two tyrosine pairs, located in $\alpha$-helix 1 and $\beta$ strand 2, are found in conjunction with a C-terminal arginine (human sequence residues 149-151 and 162-164, respectively), whereas a tyrosine pair at the $\mathrm{C}$ terminus of helix 3 (residues 225-227) is flanked by a C-terminal aspartate in mouse and hamster or a glutamine in sheep, bovine and human PrP. We reasoned that the increased solvent exposure of tyrosyl side chains in $\beta$-sheet-rich recombinant $\operatorname{PrP}$ might involve at least one such bi-tyrosine motif. Furthermore, if recombinant $\beta$-sheet-rich models some structural features of $\operatorname{PrP}^{\mathrm{Sc}}$ (refs. 10-12), antibody access to one or several TyrTyr-X motifs may provide a $\mathrm{PrP}^{\mathrm{Sc}}$-selective conformational epitope.

To test this hypothesis, rabbits were immunized with Tyr-Tyr-Arg$\mathrm{NH}_{2}$ peptides coupled through an $\mathrm{N}$-terminal cysteine residue to keyhole limpet hemocyanin (KLH). Purified rabbit IgG fractions were conjugated to magnetic beads and used in immunoprecipitation experiments with normal and prion-infected brain homogenates (see Supplementary Methods online). This bead-conjugated antibody (designated C2) specifically immunoprecipitated $\mathrm{PrP}^{\mathrm{Sc}}$ from ME7 scrapie-infected mouse brain homogenates (Fig. 2a, lanes 11 and 12; Table 1) but not $\mathrm{PrP}^{\mathrm{C}}$ from uninfected brains (Fig. 2a, lanes 9 and 10). Additionally, the C2 polyclonal antibody immunoprecipitated the protease-resistant core of $\mathrm{PrPSc}^{\mathrm{Sc}}$ $(\operatorname{PrP}(27-30))$ from protease $\mathrm{K}$-treated mouse scrapie brain homogenates (Fig. 2a, lane 12), indicating that its reactivity was not directed against the protease-sensitive domain of $\mathrm{PrP}^{\mathrm{Sc}}$ (residues 23 to $\sim 90$ ) or against a protease-sensitive coprecipitated protein. As controls, magnetic beads coupled with monoclonal antibody $6 \mathrm{H} 4$, which recognizes an epitope present on both $\mathrm{PrP}^{\mathrm{C}}$ and $\mathrm{PrP}^{\mathrm{Sc}}$ (ref. 7), immunoprecipitated $\operatorname{PrP}$ from both normal and prion-infected brain (Fig. 2a, lanes 1-4), whereas beads coupled to BSA (Fig. 2a, lanes 5-8) or preimmune sera (Table 1) precipitated neither PrP iso- form. Similar results were obtained with goat polyclonal IgG against KLH-Cys-Tyr-Tyr-Arg (Table 1).

Table 1 Species reactivity of $\mathrm{PrPS}^{\mathrm{S}}$-selective Tyr-Tyr-Arg antibodies

\begin{tabular}{|c|c|c|c|c|c|}
\hline \multicolumn{6}{|l|}{ Polyclonals } \\
\hline Rabbit C2 & ++ & + & ND & ND & ND \\
\hline Goat p165 & ++ & + & ND & ND & ND \\
\hline \multicolumn{6}{|c|}{ Monoclonals } \\
\hline $1 \mathrm{~A} 12$ & ++ & ++ & ++ & + & $+^{a}$ \\
\hline 17D10 & ++ & ++ & + & + & ++ \\
\hline 17D4 & ++ & ++ & + & + & ++ \\
\hline $16 \mathrm{~A} 18$ & ++ & ++ & + & + & $++^{a}$ \\
\hline $20 A 13$ & + & + & + & + & ND \\
\hline $1 \mathrm{~A} 7$ & ++ & + & - & + & ND \\
\hline $3 A 2$ & + & ++ & - & + & ND \\
\hline $9 A 4$ & ++ & ++ & ++ & ++ & + \\
\hline $12 \mathrm{~A} 5$ & ++ & ++ & + & + & ND \\
\hline 12B1 & ++ & ++ & ++ & ++ & $++^{b}$ \\
\hline \multicolumn{6}{|c|}{ Recombinants } \\
\hline $16 A 18$ & ++ & ND & ND & ND & ND \\
\hline $20 A 13$ & ++ & ND & ND & ND & ND \\
\hline $1 \mathrm{~A} 7$ & + & ND & ND & ND & ND \\
\hline $9 A 4$ & ++ & ND & ND & ND & ND \\
\hline $12 \mathrm{~A} 5$ & ++ & ND & ND & ND & ND \\
\hline \multicolumn{6}{|c|}{ Control antibodies } \\
\hline Rabbit pre & - & - & ND & ND & ND \\
\hline Goat pre & - & - & ND & ND & ND \\
\hline 4E4 IgM & - & - & - & - & - \\
\hline 10D4 IgM & - & - & - & - & - \\
\hline 115 lgM & - & - & - & - & - \\
\hline
\end{tabular}

Tyr-Tyr-Arg antibodies recognize PrPSc from prion-infected brains of multiple species. Reactivity (graded,-+ or ++ ) was compiled from at least three brain immunoprecipitations. ND, not determined; pre, pre-immune sera. We used mouse prion strains ME7 and 139A, hamster strain 263K and human prion disease strains variant CJD, classical sporadic CJD and GSS. ${ }^{a} \mathrm{CJD}$ and GSS only. bariant CJD only. 
We next generated Tyr-Tyr-Arg monoclonal antibodies by immunizing BALB/C mice with KLH conjugated to the peptide CYYRRYYRYY (this peptide sequence was chosen because one PrP bi-tyrosine motif is flanked by arginine at both $\mathrm{N}$ and $\mathrm{C}$ termini). Sixty monoclonal antibodies were selected by ELISA screening against the Tyr-Tyr-Arg antigen coupled to a backbone comprising branched lysines (four-branch multiple antigen peptide; 4-MAP). Ten monoclonal antibodies binding 4-MAP-Tyr-Tyr-Arg, but not control 4-MAP-Ala-Ala-Ala, were tested for $\mathrm{PrP}^{\mathrm{Sc}}$-specific recognition by immunoprecipitation as described above. All ten monoclonal antibodies displayed $\mathrm{PrP}^{\mathrm{Sc}}$-specific immunoprecipitation from scrapie-infected ME7 and 139A mouse brain or $263 \mathrm{~K}$ infected hamster brain, and from naturally prion-infected sheep and cattle (Table 1). Some monoclonal antibodies preferentially recognized $\mathrm{PrP}^{\mathrm{Sc}}$ from a subset of these species, suggesting that the monoclonal antibodies did not recognize identical epitopes, a findingsupported by peptide competition experiments (see below). Immunoprecipitation studies performed with two monoclonal antibodies (1A12 and 17D10) are shown (Fig. 2b). Magnetic beads coupled to the positive control monoclonal antibody $6 \mathrm{H} 4 \mathrm{immuno}-$ precipitated PrP from both normal and prion-infected tissues, whereas beads coupled to three isotype-control monoclonal antibodies immunoprecipitated neither PrP isoform (Fig. $2 \mathbf{b}$ and Table 1). In addition, monoclonal antibodies to Tyr-Tyr-Arg selectively immunoprecipitated $\mathrm{PrPSc}^{\mathrm{Sc}}$ from prion-infected human brain homogenates (two classical sporadic CJD, one GSS, and three variant CJD) but did not immunoprecipitate PrP from 12 brains of other neurological diseases (Fig. 2c,d, Table 1 and data not shown). Direct efficiency comparison of the sensitivity of protease $\mathrm{K}$ digestion and Tyr-Tyr-Arg monoclonal antibody immunoprecipitation showed
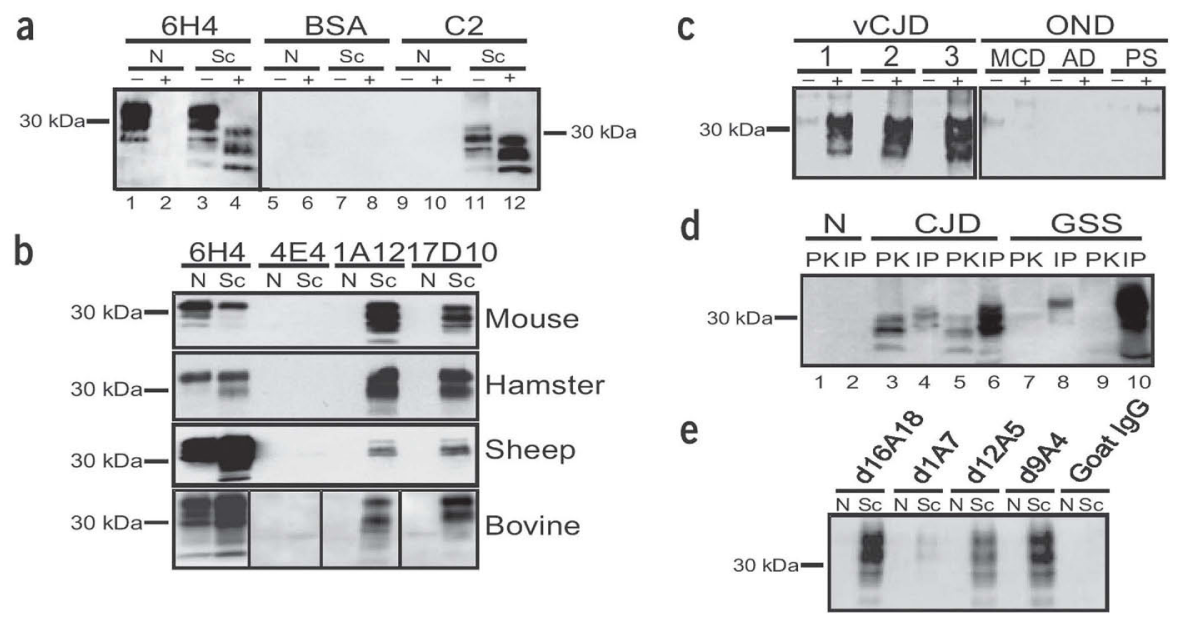

Figure 2 Tyr-Tyr-Arg antibodies selectively recognize PrPSc. (a) Rabbit polyclonal antibody (C2) selectively immunoprecipitates $\operatorname{PrPSC}$ and $\operatorname{PrP}(27-30)$ but not PrPC . C2-conjugated magnetic beads were roteinase K (PK) treatment. (b) Monoclonal antibodies 1A12 and 17D10 selectively immunoprecipitate 4E4, isotype-control monoclonal antibody. (c) 17D10 immunoprecipitates PrPSc from variant CJD D)-infected brain $(1,2,3)$ but not $\mathrm{PrPC}$ from brains with other neurological disease (OND; MCL, multifocal calcifying leucoencephalopathy; AD, Alzheimer disease; PS, paraneoplastic syndrome) +, 17D10; -, 4E4 immunoprecipitations. (d) Efficiency comparison of PK resistance and Tyr-Tyr-Arg mmunoprecipitation (monoclonal antibody 16A18) from equivalent samples of frontal $(1-4,7,8)$ and selectively precipitates $\mathrm{PrPSc}$, but not $\mathrm{PrPC}$, from scrapie-infected mouse brain homogenate. Immunoprecipitated PrP was detected by immunoblotting with $6 \mathrm{H} 4(\mathbf{a}, \mathbf{b}, \mathbf{e})$ or $3 \mathrm{~F} 4(\mathbf{c}, \mathbf{d})$.

comparable signal in most species and brain regions (Fig. 2a,d) but revealed that selected prion disease brains contain immunoprecipitatable $\mathrm{PrP}$, which is poorly resistant to protease K (Fig. $2 \mathrm{~d}$ and data not shown).

Although $\mathrm{PrP}^{\mathrm{Sc}}$-specific polyclonal IgG antibodies to Tyr-Tyr-Arg have been successfully raised in rabbits (Fig. 2a) and goats (data not shown), all mouse monoclonal antibodies to Tyr-Tyr-Arg produced to date have been IgMs, even at the screening stage. In order to exclude the possibility that $\mathrm{PrP}^{\mathrm{Sc}}$ recognition is a low-affinity interaction dependent on the high avidity conferred by ten IgM antigen-binding sites, we constructed and expressed chimeric IgG monoclonal anti- a

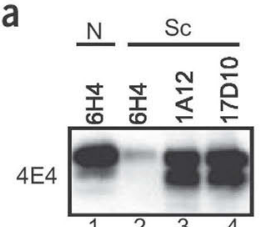

$1 \mathrm{~A} 12$

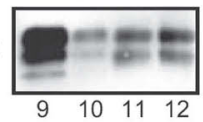

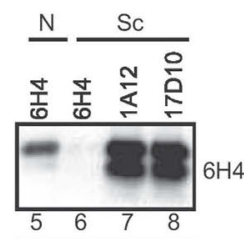

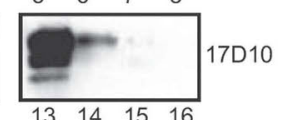

b

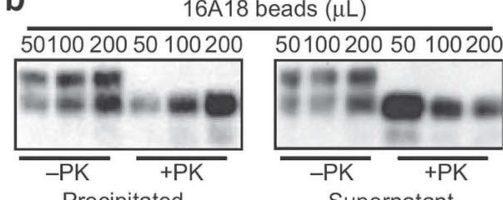

Precipitated

Supernatant

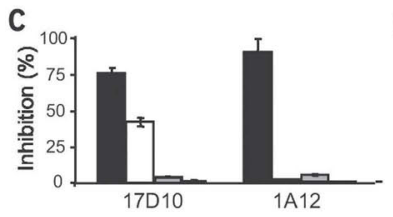

d

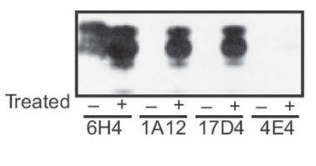

Figure 3 Characterization of PrPSc-selective antibodies. (a) PrPSc-selective antibodies and $6 \mathrm{H} 4$ recognize different sites on PrPSc. Normal (N) or scrapieinfected (Sc) hamster brain homogenates were incubated with unconjugated control IgM 4E4 (lanes 1-4), 6H4 (lanes 5-8), 1A12 (lanes 9-12) or 17D10 (lanes 13-16), followed by immunoprecipitation with magnetic bead-conjugated 6H4 (lanes 1, 2, 5, 6, 9, 10, 13 and 14), 1A12 (lanes 3, 7, 11 and 15), or 17D10 (lanes 4, 8, 12 and 16). (b) Saturability of Tyr-Tyr-Arg monoclonal antibody binding. A fixed quantity of $263 \mathrm{~K}$ scrapie brain homogenate was probed with a titration of $16 \mathrm{~A} 18$ monoclonal antibody beads followed by PK digestion. PrP(27-30) signal is proportional (immunoprecipitates directly, supernatants indirectly) to bead quantity. (c) 17D10 and 1A12 epitope characterization. ELISA data are presented as percent inhibition of binding compared to binding without peptide ( $\mathbf{\square}, 4$-MAP YYR; $\square$, 4-MAP YAR; , 4-MAP YYA; $\square$, 4-MAP AAA). Shown are means \pm s.d. ( $n=3$ ). (d) Monoclonal antibodies 1A12 and 17D10 selectively immunoprecipitate partially denatured human brain PrP. Lanes 2, 4, 6, 8: acidic pH- and guanidine HCl-treated brain samples; lanes 1, 3, 5, 7: mock-treated samples. Immunoprecipitated PrP was detected by immunoblotting with 6H4 (a-c) or 3F4 (d). 


\section{ARTICLES}

a

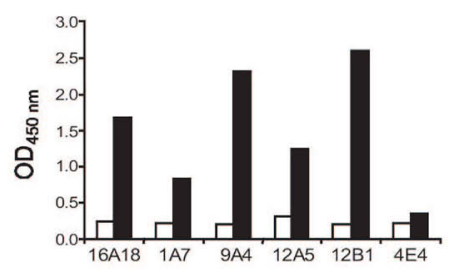

b
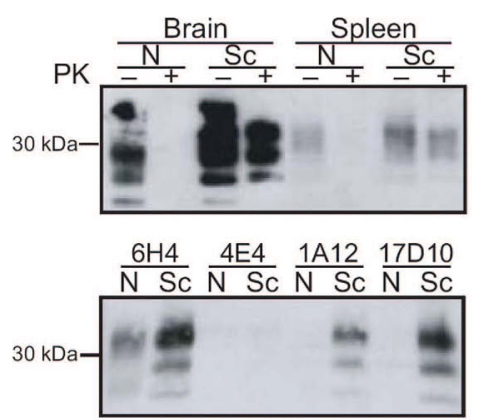

C

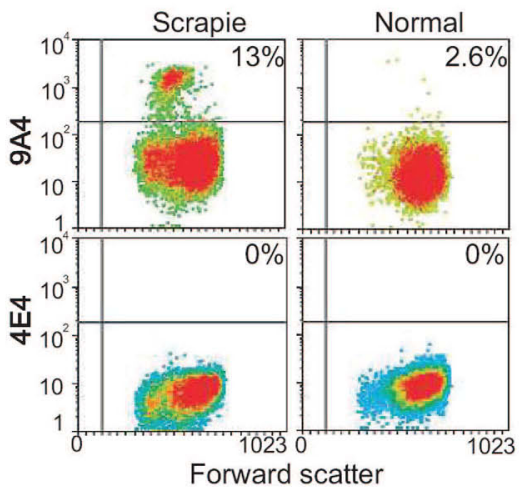

bodies from recombinant light- and heavy-chain variable regions of five different Tyr-Tyr-Arg monoclonal antibodies in a dog IgG framework ${ }^{17}$. All five recombinant bivalent $\operatorname{IgG}$ antibodies retained selective immunoprecipitation activity against $\operatorname{PrP}^{\mathrm{Sc}}$ (Fig. 2e and Table 1), consistent with a relatively high-affinity recognition of $\mathrm{PrP}^{\mathrm{Pc}}$ by the native IgM monoclonal antibodies. Tyr repeats have been reported to define a dominant B-cell epitope ${ }^{18}$, suggesting that the highly skewed $\operatorname{IgM}$ monoclonal antibody frequency we observed may be the result of a specific mouse immune response to Tyr-Tyr-Arg antigens.

\section{The PrPSc Tyr-Tyr-Arg epitope is saturable and specific}

We carried out antibody competition experiments to test the immunological authenticity of the $\mathrm{PrP}^{\mathrm{Sc}}$-selective Tyr-Tyr-Arg epitope (Fig. 3a). Scrapie-infected hamster brain homogenates were incubated overnight with soluble Tyr-Tyr-Arg monoclonal antibodies $1 \mathrm{~A} 12$ and 17D10, or the nondistinguishing PrP antibody 6H4, or the control antibody $4 \mathrm{E} 4$. These homogenates were then subjected to immunoprecipitation with the same series of antibodies covalently coupled to magnetic beads. Whereas pretreatment with soluble $1 \mathrm{~A} 12$ or 17D10 inhibited the immunoprecipitation of $\mathrm{PrP}^{\mathrm{Sc}}$ by either beadconjugated Tyr-Tyr-Arg monoclonal antibody, neither soluble 6H4 nor 4E4 monoclonal antibodies blocked $\mathrm{PrP}^{\mathrm{Sc}}$ immunoprecipitation by $1 \mathrm{~A} 12$ and $17 \mathrm{D} 10$. Similarly, $1 \mathrm{~A} 12$ and 17D10 did not block the immunoprecipitation of $\mathrm{PrP}^{\mathrm{C}}$ or $\mathrm{PrP}^{\mathrm{Sc}}$ with 6H4, despite the overlap of the reported $6 \mathrm{H} 4$ epitope and a Tyr-Tyr-Arg motif in helix 1

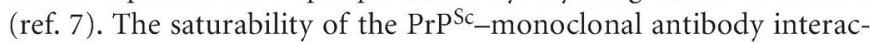
tion was also tested by titration of $263 \mathrm{~K}$ hamster scrapie brain
Figure 4 Tyr-Tyr-Arg antibodies detect PrPSc in diagnostic platforms and tissues. (a) Mouse PrPSc detected in a 96-well capture format using monoclonal antibody-conjugated beads (Tyr-Tyr-Arg monoclonal antibodies $16 \mathrm{~A} 18,1 \mathrm{~A} 7,9 \mathrm{~A} 4,12 \mathrm{~A} 5,12 \mathrm{~B} 1$; isotype-control monoclonal antibody 4E4) and an isoform-nondiscriminating rabbit polyclonal antibody to PrP N terminus ( $\square$, scrapie; $\square$, control). Results displayed as absorbance (OD) at $450 \mathrm{~nm}$. (b) Tyr-Tyr-Arg antibodies recognize low concentrations of PrPSc in ME7-infected mouse spleen. Top, normal (N) and scrapie-infected (Sc) mouse brain and spleen homogenates were mock- $(-)$ or protease $\mathrm{K}(\mathrm{PK})$ digested $(+)$ and PrP isoforms were revealed by $6 \mathrm{H} 4$ immunoblot. Bottom, Tyr-Tyr-Arg monoclonal antibodies 1A12 and 17D10 selectively precipitate $\mathrm{PrPSc}^{\mathrm{S}}$ from scrapie-infected mouse spleen. (c) Tyr-Tyr-Arg monoclonal antibody $9 \mathrm{~A} 4$ recognizes a population of dendritic cells from scrapieinfected sheep lymph nodes. $\mathrm{CD} 58^{+} \mathrm{CD} 45 \mathrm{RO} \mathrm{O}^{-}$retropharyngeal lymph node cells from scrapie-infected and normal sheep stained with 9A4 or control monoclonal antibody 4E4.

homogenate with Tyr-Tyr-Arg 16A18-conjugated beads (Fig. 3b), showing that bead quantity is proportional to $\operatorname{Pr} \mathrm{P}^{\mathrm{Sc}}$ and $\operatorname{PrP}(27-30)$ content of immunoprecipitates and supernatants. These data are consistent with specific and saturable immune recognition of a discrete $\mathrm{PrP}^{\mathrm{Sc}}$ epitope by antibodies to Tyr-Tyr-Arg.

To further characterize the Tyr-Tyr-Arg epitope, the fine specificities of 1A12 and 17D10 were determined in a peptide competition ELISA system (Fig. 3c). As expected, the two Tyr-Tyr-Arg monoclonal antibodies bound to plate-immobilized 4-MAP-Tyr-Tyr-Arg, but the isotype-control monoclonal antibody $4 \mathrm{E} 4$ and the isoformnonspecific monoclonal antibody $6 \mathrm{H} 4$ did not (data not shown). Plate binding of 1A12 and 17D10 was efficiently inhibited by soluble 4-MAP-Tyr-Tyr-Arg, but not by 4-MAP-Ala-Ala-Ala. Tyr-Tyr-Ala conjugate did not compete for binding of $1 \mathrm{~A} 12$ or 17D10, whereas Tyr-Ala-Arg conjugate partially competed for the binding of 17D 10, but not 1A12. These data suggest that 1A12 and 17D10 possess overlapping, but not identical, specificities in which all three amino-acid side chains participate in epitope recognition, although access to the terminal tyrosine and arginine residues may be more important than the central tyrosine.

Our data indicate that the $\mathrm{PrP}^{\mathrm{Sc}}$-specific Tyr-Tyr-Arg epitope must be cryptic in $\mathrm{PrP}^{\mathrm{C}}$, but exposed to antibody binding in PrP $\mathrm{P}^{\mathrm{Sc}}$. Efforts to immunoprecipitate $\beta$-sheet-rich recombinant mouse PrP treated at low $\mathrm{pH}($ Fig. 1a,b) revealed that this preparation bound nonspecifically to all tested antibodies, including isotype-control monoclonal antibodies (data not shown). However, $\operatorname{PrP}^{\mathrm{C}}$ in normal human and mouse brain homogenates treated under identical conditions ${ }^{19}$ acquires the Tyr-Tyr-Arg epitope (Fig. $3 \mathbf{d}$ and data not shown), suggesting that the tripeptide epitope is exposed when PrP is partially denatured in the context of native post-translational modifications (including two N-linked glycans and a glycosyl-phosphatidylinositol anchor).

\section{PrPSc Tyr-Tyr-Arg reactivity is platform-independent}

Using a 96-well sandwich ELISA system, we observed $\mathrm{PrP}^{\mathrm{Sc}}$ detection sensitivity with Tyr-Tyr-Arg monoclonal antibodies for capture, and a pan-PrP N-terminus polyclonal antibody for detection (Fig. 4a). In these experiments, scrapie-to-normal ratios ranged up to 25 -fold for the panel of monoclonal antibodies tested, using a 1,000-fold final dilution of mouse ME7 scrapie brain. These data suggest that TyrTyr-Arg antibodies may be useful in a robust high-throughput immunodetection system targeted against native $\operatorname{Pr} \mathrm{P}^{\mathrm{Sc}}$.

Several important natural prion diseases (such as scrapie and variant CJD) are accompanied by agent accumulation in biopsy-accessi- 
ble peripheral lymphoid tissues. In mouse spleen, however, prion titers are at least $3-4$ logs lower than those in brain ${ }^{20,21}$, and $\operatorname{PrP}(27-30)$ load in moribund animals is estimated to be at least $1-2$ logs less than that of brain ${ }^{21,22}$. Despite low levels of $\mathrm{PrP}^{\mathrm{Sc}}$ in spleen compared with brain (Fig. 4b, upper panel), Tyr-Tyr-Arg monoclonal antibodies 17D10 and 1A12 immunoprecipitated PrPSc from this tissue, but not $\operatorname{PrP}^{\mathrm{C}}$ (Fig. 4b, bottom panel). These data indicate that the sensitivity of the Tyr-Tyr-Arg monoclonal antibodies is sufficient to maintain $\operatorname{PrP}$ isoform specificity even in the presence of high concentrations of heterologous proteins.

In diseases accompanied by lymphoid replication of prions, $\mathrm{PrP}^{\mathrm{Sc}}$ preferentially accumulates in follicular dendritic cells (FDCs ${ }^{23-25}$. Retropharyngeal lymph node dendritic cells $\left(\mathrm{CD} 45 \mathrm{RO}^{-} \mathrm{CD} 58^{+}\right)$ from three of three scrapie-infected sheep displayed Tyr-Tyr-Arg surface immunoreactivity with the monoclonal antibody 9A4 (8-29\% of cells), but not the 4E4 isotype-control monoclonal antibody $(0-0.4 \%)$, whereas similar cells from three uninfected sheep did not stain with either monoclonal antibody (Fig. 4c). No significant Tyr-Tyr-Arg surface immunoreactivity was observed on sheep or rodent lymphocytes, or on dissociated brain cells from end-stage ME7 scrapie-infected mice (data not shown), suggesting that FDCs may selectively accumulate cell-surface $\operatorname{PrP}^{\mathrm{Sc}}$.

\section{DISCUSSION}

We believe that the Tyr-Tyr-Arg motif constitutes the first hypothesisdriven $\mathrm{PrP}^{\mathrm{Sc}}$-selective epitope derived from consideration of isoformselective antibody accessibility to amino-acid side chains exposed during conformational conversion in prion diseases. Tyr-Tyr-Arg antibodies, in addition to recognizing the protease-resistant $\operatorname{PrP}$ that is key to most current diagnostic tests for prion infection, can also recognize misfolded but protease-sensitive PrP (Figs. $2 d$ and $3 c$ and data not shown). In prion disease, the latter, newly recognized molecular species ${ }^{26}$ is characteristic of certain prion strains ${ }^{27}$, early prion infection ${ }^{20-22}$ and interspecies prion transmission ${ }^{28}$. Protease-sensitive $\mathrm{PrP}^{\mathrm{Sc}}$ may represent a transient intermediate between normal structure and the abnormal, misfolded and aggregated PrP isoform that has acquired protease resistance ${ }^{29}$. The population of misfolded protease-sensitive molecules may also contain $\mathrm{PrP}^{\star}$, the hypothetical PrP isoform responsible for the property of prion infectivity ${ }^{30}$.

We showed surface immunoreactivity for Tyr-Tyr-Arg on living dendritic cells from scrapie-infected sheep lymph nodes, suggesting that $\mathrm{PrP}^{\mathrm{Sc}} \mathrm{can}$ be maintained in the native (infectious) conformation on these cells. FDCs are implicated in the immune presentation to B cells of native-structure antigens, complexed at the cell surface with antibody or complement or both ${ }^{31}$. Recent studies have shown a role for complement components $\mathrm{s}^{32,33}$ and B cells ${ }^{34}$ in lymphoid replication and subsequent neuroinvasion of prions. It is thus possible that native $\mathrm{PrPSc}$, perhaps complexed with complement, may accumulate on FDCs for immune presentation to other lymphoid cells, which become concurrently infected with prions. Immune presentation of $\mathrm{PrP}^{\mathrm{Sc}}$ must be ineffectual, as no antiprion humoral or cellular immune response has been detected in prion infection ${ }^{35}$.

The $\mathrm{PrP}^{\mathrm{Sc}}$-selective Tyr-Tyr-Arg epitope may prove useful in immunotherapy or immunoprophylaxis of prion diseases. Recent findings show that antibodies directed predominantly against $\operatorname{PrP}^{\mathrm{C}}$ can clear scrapie-infected cells of $\mathrm{PrP}^{\mathrm{Sc}}$ in vitro ${ }^{36,37}$ and can block the propagation of experimental scrapie in transgenic mice in vivo ${ }^{9}$. However, autoimmune recognition of $\mathrm{PrP}^{\mathrm{C}}$ could cause inappropriate activation of signaling cascades $^{38}$, immunosuppression ${ }^{39}$ and widespread complement-dependent cellular lysis ${ }^{40}$, although in some experimental paradigms such antibodies are apparently toler- ated $^{9,41}$. Considering the key role of dendritic cells in scrapie, BSE and variant $\mathrm{CJD}^{23,24,25}$, and the immunologic recognition of dendritic cell-surface $\mathrm{PrP}^{\mathrm{Sc}}$ by Tyr-Tyr-Arg antibodies in physiological buffers (Fig. 4c), it is conceivable that circulating Tyr-Tyr-Arg antibodies could block prion neuroinvasion by neutralizing or opsonizing gut or lymphoid prions during the peripheral incubation phase of these diseases.

The isoform-selective exposure of Tyr-Tyr-Arg may help determine the structure of $\mathrm{PrPSc}$, for which only low-resolution fragmentary structures are currently available ${ }^{42}$. The three Tyr-Tyr-X motifs of $\operatorname{PrP}$ are apparently obscured to antibody recognition in $\operatorname{PrP}^{\mathrm{C}}$ by tertiary structural elements ${ }^{14-16}$ and native post-translational modi-

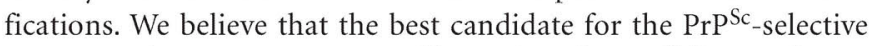
epitope is the Tyr-Tyr-Arg motif located in the $\operatorname{PrP}^{C} \boldsymbol{\beta}$-strand 2. In support of this idea, Tyr-Tyr-Arg monoclonal antibody binding is not inhibited by $6 \mathrm{H} 4$ antibody (recognizing an overlapping epitope in $\alpha$-helix 1 ; ref. 7 ), Tyr-Tyr-Arg monoclonal antibody binding seems to be critically dependent on the terminal arginine residue (lacking in the Tyr-Tyr-Gln and Tyr-Tyr-Asp sequences of $\alpha$-helix 3), and antibody access to the $C$ terminus of native $\operatorname{Pr} P(\alpha$-helix 3$)$ does not differ for $\mathrm{PrP}^{\mathrm{C}}$ and $\mathrm{PrP}^{\mathrm{Sc}}$ (ref. 43). Moreover, considering that access to all three side chains is necessary for Tyr-Tyr-Arg antibody binding, we speculate that $\beta$-strand 2 becomes exposed in disease as a result of the dissolution of the short $\beta$-sheet of $\mathrm{PrP}^{\mathrm{C}}$. This notion is consistent with experimental data indicating that $\operatorname{Pr} \mathrm{P}^{S c}$ has features of a molten globule ${ }^{12,44}$ lacking some of the tertiary structural elements of $\mathrm{PrP}^{\mathrm{C}}$.

The prion diseases may provide a prototype for disorders of protein misfolding, including Alzheimer disease, amyotrophic lateral sclerosis and Parkinson disease. We hypothesize that conformational conversion of proteins in disease is accompanied by molecular surface exposure of previously sequestered amino-acid side chains. It is possible that exploitation of this 'side-chain accessibility' hypothesis, applied here to isoform-selective antibodies for PrP, may provide new diagnostic and therapeutic approaches to other post-translational disorders of the proteome.

\section{METHODS}

Tyrosine and tryptophan fluorescence at varying $\mathrm{pH}$. Recombinant mouse $\operatorname{PrP}(23-231)$ (400 nM; gift of K. Qin and D. Westaway, University of Toronto) dissolved in $1.5 \mathrm{M}$ guanidine hydrochloride (Sigma), $2 \mathrm{mM}$ sodium phosphate (Sigma) and $2 \mathrm{mM}$ sodium citrate (Sigma) buffers was monitored by steady-state fluorescence using a $2 \mathrm{~nm}$ bandpass. The excitation and emission wavelengths were $275 \mathrm{~nm}$ and $310 \mathrm{~nm}$ for tyrosine fluorescence and $293 \mathrm{~nm}$ and $350 \mathrm{~nm}$ for tryptophan fluorescence measurements, respectively.

Acrylamide quenching of tyrosine fluorescence. $\operatorname{PrP}(23-231)(400 \mathrm{nM})$ in $1.5 \mathrm{M}$ guanidine hydrochloride, $2 \mathrm{mM}$ sodium phosphate and $2 \mathrm{mM}$ sodium citrate was titrated with increasing concentrations of acrylamide (Sigma) at $\mathrm{pH}$ values of 7 and 3 . Tyrosine fluorescence was measured using an excitation wavelength of $275 \mathrm{~nm}$ (bandpass of $2 \mathrm{~nm}$ ) and an emission wavelength of 311 $\mathrm{nm}$ (bandpass of $7 \mathrm{~nm}$ ). Stern-Volmer plots were obtained by plotting the ratio of the observed fluorescence in the absence of acrylamide to the fluorescence in the presence of acrylamide.

Antibody generation. Polyclonal antibody $\mathrm{C} 2$ was produced by immunizing rabbits with KLH-conjugated Cys-Tyr-Tyr-Arg peptide. IgG from sera were purified on a protein A-Sepharose column (Pharmacia Amersham). Monoclonal antibodies were developed by immunizing and thrice boosting mice with KLH-conjugated CYYRRYYRYY peptide, in Freund complete adjuvant. Initial screening was done by testing antibody reactivity on 4-MAPTyr-Tyr-Arg-coated plates. Positive IgM was purified by size fractionation from ascites fluid. Monoclonal antibody variable regions were cloned into a 
dog IgG framework from cDNA produced from hybridomas by PCR amplification. Light- and heavy-chain variable regions were amplified using forward primers specific to the leader sequences and reverse primers specific to the first exon of the constant regions. Dog light- and heavy-chain constant regions were amplified in a similar fashion. PCR products were annealed and amplified using primers specific to the outer ends. Overlapped light- and heavy-chain PCR fragments were cloned into pcDNA3 vectors. Plasmid DNA was transfected into 293 cells, at a 3:1 light-to-heavy chain molar ratio, using Lipofectamin2000 (Invitrogen) under standard conditions. Recombinant chimeric IgGs were purified on protein A-Sepharose. A polyclonal nondistinguishing antibody against $\operatorname{PrP}$ was produced by immunizing rabbits with a peptide corresponding to residues $23-56$ of bovine PrP. IgG was purified from sera as described above.

Preparation of acidic guanidine-HCl-treated PrP. We mixed $100 \mu \mathrm{l}$ of $10 \%$ brain homogenate with an equal volume of $3.0 \mathrm{M}$ guanidine $\mathrm{HCl}$ (final concentration $1.5 \mathrm{M}$ ) in $\mathrm{PBS}$ at $\mathrm{pH} 7.4$ or $\mathrm{pH} 3.5$ adjusted with $1 \mathrm{~N} \mathrm{HCl}$, followed by incubation at room temperature with shaking. After $5 \mathrm{~h}$, samples were mixed with five volumes of prechilled methanol and incubated at $-20^{\circ} \mathrm{C}$ for $2 \mathrm{~h}$ to precipitate the proteins. The samples were subjected to centrifugation at $16,000 \mathrm{~g}$ for $20 \mathrm{~min}$ at $4{ }^{\circ} \mathrm{C}$ to remove the acidic buffer and guanidine $\mathrm{HCl}$, and pellets were resuspended in $100 \mu \mathrm{l}$ of lysis buffer. The samples treated at pH 7.4 were designated as mock-treated samples.

Peptide ELISA. Hybridoma supernatants were produced by culturing hybridoma cells in DMEM (Wisent) supplemented with 20\% FBS (Wisent). The culture medium was separated from the cells by centrifugation $(1,000 \mathrm{~g})$ for $10 \mathrm{~min}$. Supernatants were diluted one-third in medium with $10 \%$ FCS and incubated with the indicated 4-MAP-peptide conjugates at $1 \mathrm{mg} / \mathrm{ml}$ final concentration for $2 \mathrm{~h}$ at $20-24^{\circ} \mathrm{C}$. Immulon-4 96-well plates (Dynex) were coated with $100 \mu \mathrm{l}$ of peptide diluted to $10 \mu \mathrm{g} / \mathrm{ml}$ in $100 \mathrm{mM}$ carbonate buffer $(\mathrm{pH}$ 9.6). The coated plates were blocked with PBS and 1\% BSA (Sigma) for $2 \mathrm{~h}$ at room temperature. The supernatant mixtures were added to the 4-MAP-Tyr-Tyr-Arg-coated plates for $30 \mathrm{~min}$. After 6-8 washes with PBS and $0.5 \%$ Tween 20 , bound antibody was revealed using a horseradish peroxidase-labeled goat antibody to mouse immunoglobulin, diluted 1:3,000.

Bead ELISA. Five microliters of mouse $10 \%$ brain homogenates were incubated with $15 \mu \mathrm{l}$ of magnetic bead-conjugated antibodies to Tyr-Tyr-Arg in $0.2 \mathrm{ml}$ of immunoprecipitation binding buffer for $2 \mathrm{~h}$ at $20-24^{\circ} \mathrm{C}$ with shaking. Washes were done in a similar fashion to the usual immunoprecipitation. Captured $\operatorname{PrP}^{\mathrm{Sc}}$ was detected with purified rabbit $\operatorname{IgG}$ to $\operatorname{PrP}$, followed by horseradish peroxidase-labeled donkey antibody to rabbit immunoglobulin (Jackson), diluted 1:1,000.

Flow cytometry. Fresh retropharyngeal lymph nodes from normal and scrapie-infected sheep were processed as modified from ref. 45 . The tissue was dissected into small chunks and incubated three times, at $37^{\circ} \mathrm{C}$ for $15 \mathrm{~min}$, with a solution containing $0.15 \mathrm{mg} / \mathrm{ml}$ Blenzyme I (Roche Diagnostics) and $0.03 \mathrm{mg} / \mathrm{ml}$ DNase I (Roche Diagnostics). Viable lymph node cells were sequentially incubated for $15 \mathrm{~min}$ on ice with normal mouse serum, antibody to sheep CD58 (VMRD, Inc.), phycoerythrin-conjugated goat antibody to mouse IgG1 (Southern Biotech Associates), antibody to sheep CD45RO (VMRD, Inc.), biotin-conjugated goat antibody to mouse IgG3 (Southern Biotech Associates), phycoerythrin-Cy5-conjugated streptavidin (Serotec) and $10 \mu \mathrm{g} / \mathrm{ml}$ of either a $\mathrm{PrP}^{\mathrm{Sc}}$-specific antibody or the isotype control, followed by FITC-conjugated goat antibody to mouse IgM (Southern Biotech Associates). All antibody dilutions and washes were done using Dulbecco PBS supplemented with $2.5 \%$ FBS.

Note: Supplementary information is available on the Nature Medicine website.

\section{ACKNOWLEDGMENTS}

We thank A. Aguzzi, C. Bergeron, R. Jackman, R. Carp, B. Oesch, R. Rohwer, R. Rubinstein and M. J. Schmerr for provision of infected material and facilities; K. Qin and D. Westaway for recombinant mouse PrP; B. Bartol, P. Cunningham, P. Cecchetti, B. O'Brien-Graf, C. Quan and E. Thibaudeau for expert technical assistance; D. Chelsky and J. Griffin for critical reading of the manuscript; and
C. Desjardins and L. Segal for their encouragement and support of this work. N.R.C. is the Jeno and Ilona Diener Chair of Neurodegenerative Diseases at the University of Toronto and Sunnybrook \& Women's College Health Sciences Center, and is a Founder and Scientific Advisor of Caprion Pharmaceuticals. This work was supported by Caprion Pharmaceuticals, the Canadian Institutes of Health Research (Institute of Infection and Immunity) and McDonald's Corporation.

\section{COMPETING INTERESTS STATEMENT}

The authors declare competing financial interests (see the Nature Medicine website for details).

Received 6 October 2002; accepted 17 April 2003.

Published online 1 June 2003; doi:10.1038/nm883

1. Prusiner, S.B. Prions. Proc. Natl. Acad. Sci. USA 95, 13363-13383 (1998).

2. Will, R.G. et al. A new variant of Creutzfeldt-Jakob disease in the UK. Lancet 347 , 921-925 (1996).

3. Coulthart, M.B. \& Cashman, N.R. Variant Creutzfeldt-Jakob disease: a summary of current scientific knowledge in relation to public health. Can. Med. Assoc. J. 165, 51-58 (2001).

4. Bolton, D.C., McKinley M.P. \& Prusiner S.B. Identification of a protein that purifies with the scrapie prion. Science 218, 1309-1311 (1982).

5. Pan, K.-M. et al. Conversion of alpha-helices into beta-sheets features in the formation of the scrapie prion proteins. Proc. Natl. Acad. Sci. USA 90, 10962-10966 (1993).

6. Pergami, P., Jaffe, H. \& Safar, J. Semipreparative chromatographic method to purify the normal cellular isoform of the prion protein in nondenatured form. Anal. Biochem. 236, 63-73 (1996).

7. Korth, C. et al. Prion ( $\mathrm{PrPS}^{\mathrm{Sc}}$-specific epitope defined by a monoclonal antibody. Nature 390, 74-77 (1997).

8. Fischer, M.B., Roeckl, C., Parizek, P., Schwarz, H.P. \& Aguzzi, A. Binding of disease-associated prion protein to plasminogen. Nature 408, 479-483 (2000).

9. Heppner, F.L. et al. Prevention of scrapie pathogenesis by transgenic expression of anti-prion protein antibodies. Science 294, 178-182 (2001).

10. Swietnicki, W., Petersen, R., Gambetti, P. \& Surewicz, W.K. pH-dependent stability and conformation of the recombinant human prion protein $\operatorname{PrP}(90-231)$. J. Biol. Chem. 272, 27517-27520 (1997).

11. Hornemann, S. \& Glockshuber, R. A scrapie-like unfolding intermediate of the prion protein domain $\operatorname{PrP}(121-231)$ induced by acidic pH. Proc. Natl. Acad. Sci. USA 95, 6010-6014 (1998).

12. Jackson, G.S. et al. Reversible conversion of monomeric human prion protein between native and fibrillogenic conformations. Science 283, 1935-1937 (1999).

13. Cioni, P. Oxygen and acrylamide quenching of protein phosphorescence: correlation with protein dynamics. Biophys. Chem. 87, 15-24 (2000).

14. Riek, R. et al. NMR structure of the mouse prion protein domain $\operatorname{PrP}(121-321)$. Nature 382, 180-182 (1996).

15. Liu, H. et al. Solution structure of Syrian hamster prion protein recombinant PrP(90-231). Biochemistry 38, 5362-5377 (1999)

16. Zahn, R. et al. NMR solution structure of the human prion protein. Proc. Natl. Acad. Sci. USA 97, 145-150 (2000).

17. Tang, L., Sampson, C., Dreitz, M.J. \& McCall, C. Cloning and characterization of cDNAs encoding four different canine immunoglobulin gamma chains. Vet. Immunol. Immunopathol. 80, 259-270 (2001).

18. Sela, M., Mozes, E., Zisman, E., Muszkat, K.A. \& Schechter, B. A tale of two peptides, TyrTyrGluGlu and TyrGluTyrGlu, and their diverse immune behaviour. Behring Inst. Mitt. 91, 54-66 (1992).

19. Zou, W-Q. \& Cashman N.R. Acidic pH and detergents enhance in vitro conversion of human brain $\mathrm{PrPC}^{\mathrm{C}}$ to a PrPSc-like form. J. Biol. Chem. 277, 43942-43947 (2002).

20. Rubenstein, R et al. Scrapie-infected spleens: analysis of infectivity, scrapie-associated fibrils, and protease-resistant proteins. J. Infect. Dis. 164, 29-35 (1991).

21. Race, R.E. \& Ernst, D. Detection of proteinase K-resistant prion protein and infectivity in mouse spleen by 2 weeks after scrapie agent inoculation. J. Gen. Virol. 73, 3319-3323 (1992).

22. Tatzelt, J., Groth, D.F., Torchia, M., Prusiner, S.B. \& DeArmond, S.J. Kinetics of prion protein accumulation in the CNS of mice with experimental scrapie. J. Neuropathol. Exp. Neurol. 58, 1244-1249 (1999).

23. Lezmi, S., Bencsik, A. \& Baron, T. CNA42 monoclonal antibody identifies FDC as PrPsc accumulating cells in the spleen of scrapie affected sheep. Vet. Immunol. Immunopathol. 82, 1-8 (2001).

24. Hill, A.F. et al. Investigation of variant Creutzfeldt-Jakob disease and other human prion diseases with tonsil biopsy samples. Lancet 353, 183-189 (1999).

25. Mabbot, N.A. \& Bruce M.E. The immunobiology of TSE diseases. J. Gen. Virol. 82 , $2307-2318(2001)$

26. Safar, J.G. et al. Measuring prions causing bovine spongiform encephalopathy or chronic wasting disease by immunoassays and transgenic mice. Nat. Biotechnol. 20, 1147-1150 (2002)

27. Safar, J.G. et al. Eight prion strains have $\operatorname{PrP}(\mathrm{Sc})$ molecules with different conformations. Nat. Med. 4, 1157-1165 (1998).

28. Hill A.F. et al. Species-barrier-independent prion replication in apparently resistant 
A RTICLES

species. Proc. Natl. Acad. Sci. USA 97, 10248-10253 (2000).

29. Horiuchi M., Priola S.A., Chabry J. \& Caughey B. Interactions between heterologous forms of prion protein:binding, inhibition of conversion, and species barriers. Proc. Natl Acad. Sci. USA 97, 5836-5841 (2000).

30. Aguzzi A. \& Weissmann C. Prion research: the next frontiers. Nature 389 795-798 (1997).

31. Szakal, A.K. \& Tew, J.G. Follicular dendritic cells: B-cell proliferation and maturation. Cancer Res, 52, 5554s-5556s (1992).

32. Klein, M.A. et al. Complement facilitates early prion pathogenesis. Nat. Med. 7 , 488-492 (2001).

33. Mabbott, N.A. et al. Temporary depletion of complement component C3 or genetic deficiency of $\mathrm{Clq}$ significantly delays onset of scrapie. Nat. Med. 7 , 485-487 (2001).

34. Klein, M.A. et al. A crucial role for B cells in neuroinvasive scrapie. Nature 390 , 687-690 (1997).

35. Gajdusek, D.C. Unconventional viruses causing subacute spongiform encephalopathies. in Virology (ed. Fields, B.N.) 1516-1557 (Raven Press, New York, 1986).

36. Enari, M., Flechsig, E. \& Weissmann, C. Scrapie prion protein accumulation by scrapie-infected neuroblastoma cells abrogated by exposure to a prion protein antibody. Proc. Natl. Acad. Sci. USA 98, 9295-9299 (2001).
37. Peretz, D. et al. Antibodies inhibit prion propagation and clear cell cultures of prion infectivity. Nature 412, 739-743 (2001).

38. Mouillet-Richard, S. et al. Signal transduction through prion protein. Science 289, 1925-1928 (2000).

39. Cashman, N.R. et al. Cellular isoform of the scrapie agent protein participates in lymphocyte activation. Cel/ 61, 185-192 (1990)

40. Bendheim, P.E. et al. Nearly ubiquitous tissue distribution of the scrapie agent precursor protein. Neurology 42, 149-156 (1992).

41. White, A.R. et al. Monoclonal antibodies inhibit prion replication and delay the development of prion disease. Nature 422, 80-83 (2003).

42. Wille, H. et al. Structural studies of the scrapie prion protein by electron crystallography. Proc. Natl. Acad. Sci. USA 99, 3563-3568 (2002).

43. Peretz, D. et al. A conformational transition at the $\mathrm{N}$ terminus of the prion protein features in formation of the scrapie isoform. J. Mol. Biol. 273, 614-622 (1997).

44. Safar, J., Roller, P.P., Gajdusek, D.C. \& Gibbs, C.J. Jr. Scrapie amyloid (prion) protein has the conformational characteristics of an aggregated molten globule folding intermediate. Biochemistry 33, 8375-8383 (1994).

45. Szakal, A.K., Gieringer, R.L., Kosco, M.H \& Tew J.G. Isolated follicular dendritic cells: cytochemical antigen localization, Nomarski, SEM, and TEM morphology. J. Immunol. 134, 1349-1359 (1985). 